\title{
Reciprocal regulation of A-to-I RNA editing and the vertebrate nervous system
}

\author{
Andrew C. Penn ${ }^{1,2}$, Ales Balik ${ }^{3}$ and Ingo H. Greger ${ }^{4 *}$ \\ 1 Interdisciplinary Institute for Neuroscience, Université de Bordeaux, UMR 5297, Bordeaux, France \\ ${ }^{2}$ CNRS, Interdisciplinary Institute for Neuroscience, UMR 5297, Bordeaux, France \\ ${ }^{3}$ Department of Neurophysiology, Institute of Physiology, Academy of Sciences of the Czech Republic v.vi.i, Prague, Czech Republic \\ ${ }^{4}$ Neurobiology Division, MRC Laboratory of Molecular Biology, Cambridge, UK
}

\section{Edited by:}

Jernej Ule, MRC Laboratory of

Molecular Biology, UK

Reviewed by:

Peter Scheiffele, University of Basel, Switzerland

Beth Wilmot, Oregon Health \&

Science University, USA

*Correspondence:

Ingo H. Greger, Neurobiology

Division, MRC Laboratory of

Molecular Biology, Francis

Crick Avenue, Hills Road,

Cambridge $\mathrm{CB} 2 \mathrm{OQH}$, UK.

e-mail:ig@mrc-Imb.cam.ac.uk
The fine control of molecules mediating communication in the nervous system is key to adjusting neuronal signaling during development and in maintaining the stability of established networks in the face of altered sensory input. To prevent the culmination of pathological recurrent network excitation or debilitating periods of quiescence, adaptive alterations occur in the signaling molecules and ion channels that control membrane excitability and synaptic transmission. However, rather than encoding (and thus "hardwiring") modified gene copies, the nervous systems of metazoa have opted for expanding on post-transcriptional pre-mRNA splicing by altering key encoded amino acids using a conserved mechanism of A-to-I RNA editing: the enzymatic deamination of adenosine to inosine. Inosine exhibits similar base-pairing properties to guanosine with respect to tRNA codon recognition, replication by polymerases, and RNA secondary structure (i.e.,: forming-capacity). In addition to recoding within the open reading frame, adenosine deamination also occurs with high frequency throughout the non-coding transcriptome, where it affects multiple aspects of RNA metabolism and gene expression. Here, we describe the recoding function of key RNA editing targets in the mammalian central nervous system and their potential to be regulated. We will then discuss how interactions of A-to-I editing with gene expression and alternative splicing could play a wider role in regulating the neuronal transcriptome. Finally, we will highlight the increasing complexity of this multifaceted control hub by summarizing new findings from high-throughput studies.

\section{Keywords: AMPA receptor, A-to-I RNA editing, dynamics of RNA editing, R/G editing site, ADAR2}

\section{A-TO-I RNA EDITING IN THE VERTEBRATE NERVOUS SYSTEM}

Although progress has been made in characterizing the functions of invertebrate editing sites, the challenge of understanding the true scale and roles of RNA editing in regulating neurophysiology in higher vertebrates continues at a somewhat slower pace. In particular, the impact of editing in non-coding regions, which harbor the vast majority of editing sites (see below) is not known. Base changes via RNA editing expand on the central dogma of molecular biology by readjusting the genetic code at the RNA level in order to substitute amino acids (Rosenthal and Seeburg, 2012). Remarkably, this occurs at functionally critical positions in targets mediating synaptic transmission. For example, editing of the $\alpha 3$ subunits of $\mathrm{GABA}_{\mathrm{A}}$ receptor ion channels modulates agonist potency and receptor gating properties to tune inhibition (Ohlson et al., 2007; Rula et al., 2008). Similarly, at excitatory synapses A-to-I editing is responsible for a number of recoding events in many of the non-NMDA glutamate receptor ion channel subunits (AMPA GluA2, 3, 4, and kainate GluK1, 2; Sommer et al., 1991; Köhler et al., 1993; Lomeli et al., 1994), including the efficient $\mathrm{Q} / \mathrm{R}$ site conversion of GluA2, which gates calcium permeability and receptor trafficking that are essential for survival (Sommer et al., 1991; Burnashev et al., 1992; Brusa et al., 1995; Greger et al., 2002). More generally, membrane excitability is modified by A-to-I editing of select subunits of voltage-gated potassium (Kv1.1) and calcium (Cav1.3) channels resulting in altered channel inactivation properties (Bhalla et al., 2004; Huang et al., 2012). Neuromodulatory control by serotonin is also targeted, where A-to-I editing of the metabotropic receptor $5-\mathrm{HT}_{2 \mathrm{C}}$ attenuates coupling to its $\mathrm{G}$-protein second messenger system (Burns et al., 1997). Furthermore, editing could also regulate serotonin signaling more globally by modifying activity of the enzyme tryptophan hydroxylase-2 (TPH2, Grohmann et al., 2010), which is rate-limiting for serotonin synthesis in the brain (Zhang et al., 2004). As the list of non-synonymous codonchanges in neuron-related transcripts continues to grow (e.g., Danecek et al., 2012), it appears that A-to-I RNA editing is poised to directly tune the function of key nervous system components. This is particularly evident in invertebrates where recoding sites are more frequent and where functional changes have been elucidated (e.g., Rosenthal and Bezanilla, 2002; Hoopengardner et al., 2003; Colina et al., 2010). In fact, a recent study showed that editing of delayed rectifier potassium channels mediates temperature adaptation (Garrett and Rosenthal, 2012) to compensate 
for an overall slower signaling at low temperatures, editing accelerates gating kinetics of this potassium channel in Arctic and Antarctic squid species relative to their tropical relatives (Garrett and Rosenthal, 2012). Invertebrate RNA editing is beyond the scope of our discussion and so we refer the reader to some recent reviews (Jepson and Reenan, 2008; Rieder and Reenan, 2012).

\section{DEVELOPMENTAL REGULATION OF A-TO-I EDITING}

The deamination reactions responsible for A-to-I editing are catalyzed by a family of "editases": adenosine deaminases acting on RNA (ADARs). The relatively high inosine content of brain mRNA (Paul and Bass, 1998), seizure susceptibility and lethal neurological phenotype of ADAR2 knockout mice (Higuchi et al., 2000), and the overall more selective expression of ADARs in the nervous system suggest that A-to-I editing contributes to refining neuronal function in development and during adult forms of synaptic plasticity. Developmental elevation of editing at various sites for many coding targets has been shown recently using new high-throughput sequencing technologies (Wahlstedt et al., 2009). These findings concur with earlier, more detailed studies on specific sites (e.g., Bernard and Khrestchatisky, 1994; Lomeli et al., 1994; Rula et al., 2008; Huang et al., 2012; Irimia et al., 2012). Age-dependent increases have also been documented for editing of small, non-coding RNA sequences, such as microRNAs (miRNAs), which typically bind to $3^{\prime}$ untranslated regions (UTRs) of transcripts to signal their degradation (Ekdahl et al., 2012). The potential for cross-talk between editing and gene expression control mechanisms in regulating neuronal development is exemplified with the case-study of miRNA cluster 379-410 (Ekdahl et al., 2012; Vesely et al., 2012). Here, editing in the critical seed regions of miRNA-381 and 376b prevents binding to Pumilio 2 (Pum2) mRNA, which codes for a translational repressor serving to negatively regulate outgrowth of neuronal dendrites. Consistent with this, developmental changes in editing of these miRNAs correlated with increased expression of Pum2 (Ekdahl et al., 2012). The increasing discovery of edits in non-coding sequences and the enrichment of some ADARs in the nervous system make it tempting to postulate that some observed tissue-specific expression patterns could result from editing-dependent switches in miRNA seed regions (Kawahara et al., 2007) or 3'-UTRs (Borchert et al., 2009), or from ADAR-modulated processing of microRNAs (Yang et al., 2006; Heale et al., 2009). Indeed, transcription profiling of the brain of ADAR2 knockout mice indicates editing could regulate the expression of a large number of genes (Horsch et al., 2011). Intriguingly, the genetic impact of A-to-I editing may be underestimated from mouse models since a disproportionately large amount of editing in humans also occurs in embedded primate-specific Alu elements that likely function to regulate gene expression (Maas, 2010).

\section{CROSS-TALK BETWEEN A-TO-I EDITING AND ALTERNATIVE SPLICING}

In addition to interactions with gene-expression control mechanisms, cross-talk exists between A-to-I editing and alternative splicing. Developmentally regulated, evolutionarily conserved
RNA editing of transcripts encoding the central nervous system (CNS)-specific alternative splicing factor Nova1, reduces its degradation by the proteasome thereby increasing Noval protein levels (Irimia et al., 2012). Noval is expressed most in the ventral spinal cord where it is essential for normal postnatal motor function and notably regulates alternative splicing of multiple inhibitory synaptic targets, including the major scaffold protein gephyrin and the $\gamma 2$ and $\alpha 2$ subunits of the $\mathrm{GABA}_{\mathrm{A}}$ and glycine receptor ion channels, respectively (Jensen et al., 2000; Ule et al., 2005). It remains to be determined how changes in editing of endogenous Noval impact on the splicing of its targets, and whether or not aberrant Noval editing could aggravate motor neuron demise in sporadic amyotrophic lateral sclerosis (ALS); a condition strongly associated with deficient ADAR2 expression and GluA2 Q/R site editing (e.g., Hideyama et al., 2010, 2012). Feedback regulation of editing exists and occurs directly via alternative splicing: ADAR2 regulates splicing of its own pre-mRNA by creating a new splice acceptor site via its A-to-I editing activity. This causes an insertion of 47 nucleotides into the coding sequence and a frameshift resulting in a truncated, catalytically inactive protein (Rueter et al., 1999; Slavov and Gardiner, 2002; Feng et al., 2006). Another interesting example demonstrating the interaction of A-to-I editing with other RNA processes occurs in the $5-\mathrm{HT}_{2 \mathrm{C}}$ receptor pre-mRNA. Here, an alternative splice donor site (necessary for the coding of a full-length receptor isoform) is silenced by a sequence element, which is weakened either by RNA editing (Flomen et al., 2004) or by an editingindependent mechanism that involves base-pairing of a small nucleolar RNA (snoRNA) HBII-52 (Kishore and Stamm, 2006). Consequently, neurons employ an unusual mechanism to regulate the editing of full-length $5-\mathrm{HT}_{2} \mathrm{C}$ receptors, which is significant in maintaining a normal serotonergic system and its associated impact on cognition and behavior (Kishore and Stamm, 2006; Doe et al., 2009; Morabito et al., 2010). Editing-dependent changes in splicing efficiency are also pivotal for AMPA-type glutamate receptor subunits: the essential $Q / R$ recoding event in the GluA2 subunit, which controls ion channel calcium permeability, is associated with more efficient pre-mRNA splicing (Brusa et al., 1995). As a result, coupled editing and splicing ensures a significantly high fraction of Q/R-edited GluA2 mRNA to tolerate modest changes in ADAR2 activity (Schoft et al., 2007; Hideyama et al., 2012; Penn et al., 2013). Also in GluA2, a correlation between $\mathrm{R} / \mathrm{G}$ site editing and alternative splice site selection appears to reflect a coupling associated with the homeostatic control of AMPA receptor biogenesis and function selectively in the CA1 region of the hippocampus (Penn et al., 2012; Balik et al., 2013).

\section{NEURONAL ACTIVITY DRIVEN REGULATION OF RNA EDITING}

The prospect of activity-dependent changes in A-to-I editing is an exciting recent development. There are various studies describing changes in A-to-I editing in diseases including ALS, epilepsy, and cancer, which mostly involve the GluA2 Q/R site and are associated with $\mathrm{Ca}^{2+}$ influx through AMPA receptors (Krestel et al., 2004; Maas et al., 2006). Another target is the serotonin receptor; of which altered G-protein coupling efficiencies 
of the $5-\mathrm{HT}_{2} \mathrm{C}$ receptor have been implicated in neuropsychiatric disorders (e.g., Gurevich et al., 2002; Bhansali et al., 2007; O'Neil and Emeson, 2012). However, one feature underlying many of these findings is that the pathological insults tend to have a dramatic impact on neuronal activity (e.g., stress, kindling, ischemia,). Some evidence points to a control of editing fundamentally by neuronal signaling. Early reports showed that serotonergic signaling via $5-\mathrm{HT}_{2} \mathrm{C}$ receptor could regulate editing of its own transcript to feedback onto the strength of receptor G-protein coupling (Gurevich et al., 2002). The same group later showed that the effect of a serotonin-selective reuptake inhibitor could reverse stress-induced changes in $5-\mathrm{HT}_{2} \mathrm{C}$ editing (Englander et al., 2005). Recent work in neuronal cultures derived from cerebral cortex has demonstrated that pharmacologically induced changes in neuronal activity can impact on ADAR targets (Orlandi et al., 2011; Sanjana et al., 2012). Altering neuronal activity in cultured hippocampal slices revealed analogous results, which turned out to be cell-type specific: editing changes occurred in the CA1, but not in CA3 subfield, which are composed of functionally and anatomically diverse neuronal cell types (Balik et al., 2013). Therefore, A-to-I editing has the capacity to fine-tune signaling in select neuronal circuitries. In two independent studies, chronic treatments lead to similar changes in AMPA receptor R/G site editing and concurrent changes in ADAR2 expression levels (Sanjana et al., 2012; Balik et al., 2013), which was also accompanied by regulation of ADAR2 self-editing (Balik et al., 2013). Interestingly, a recent study used a reporter based on the R/G site substrate to screen for repressors of ADAR2-mediated editing and identified three RNAbinding proteins (Tariq et al., 2013). The expression of two of these candidates, the splicing factor SFRS9 and the RNA helicase DDX15, was found to be regulated during mouse development and also responded to activity manipulations in CA1 of cultured hippocampal slices (Tariq et al., 2013). Binding of these factors around the $\mathrm{R} / \mathrm{G}$ site might inhibit editing either by competing with ADAR2 for the substrate and/or by interacting directly with editase to reduce its activity (Tariq et al., 2013). A characterization of the physiological impact of editing site regulation in the plasticity of neuronal functions as well as an elucidation of celltype/state specific changes in editing is now crucial and a very exciting prospect.

\section{MECHANISMS UNDERLYING ADAR REGULATION}

The mechanisms underlying editing regulation are currently unclear. These partly involve changes in ADAR levels (Balik et al., 2013), which, in the case of ADAR2, are under negative feedback control (Feng et al., 2006). However, this will depend on the efficiency of editing for a given ADAR substrate and is less likely to be relevant for strongly edited sites (Balik et al., 2013), such as the GluA2 Q/R site, for example. The "strength" of editing varies during development (Lomeli et al., 1994; Wahlstedt et al., 2009) and may be regulated in a cell- or tissue-selective manner. High-throughput sequencing data from cell lines imply overall low levels of editing (e.g., Bahn et al., 2012), but how this relates to editing levels in tissue remains to be established. Earlier reports described changes in ADAR expression levels during development (e.g., Paupard et al., 2000; Hang et al., 2008), but have recently been challenged as being responsible for observed editing site changes (Jacobs et al., 2009; Wahlstedt et al., 2009). Over the last decade, a great deal of emphasis has been placed on identifying and characterizing ADAR isoforms arising from alternatively spliced exons and transcription start sites (George et al., 2011). The varying activity of different ADAR isoforms has been described for some editing sites and so has their regulated expression during brain development (George et al., 2011), and the control of ADAR1 transcript levels by microRNAs (miRNA-1, Lim et al., 2005). The enigmatic, brain-specific (but non-catalytic) ADAR3 protein has been proposed to act in a dominant negative fashion on targets of other ADARs in vitro (Chen et al., 2000), but still little is known about its role and significance (Nishikura, 2010). More recently, protein structural studies have revealed candidates for the modulation of ADAR protein function. The ADAR2 catalytic domain contains a structurally integral inositol hexakisphosphate $\left(\mathrm{IP}_{6}\right)$ required for efficient editing activity (MacBeth et al., 2005). An intriguing postulation is that elevated $\mathrm{IP}_{6}$ formed from phospholipase $\mathrm{C}$ (PLC) following $5-\mathrm{HT}_{2} \mathrm{C}$ activation might increase activity of nascent ADAR2 protein and account for some of the feedback onto $5-\mathrm{HT}_{2 \mathrm{C}}$ receptor editing (Schmauss et al., 2010). However, further work is required to determine whether or not levels of $\mathrm{IP}_{6}$ in neurons are rate-limiting for ADAR2 activity. Post-translational modifications have also been shown to regulate ADAR protein function or abundance, including SUMOylation, phosphorylationdependent propyl-isomerization and ubiquitination (Desterro et al., 2005; Marcucci et al., 2011). Furthermore, the control of dynamic associations of ADARs with subcellular compartments has been proposed as a means to sequester functional ADARs away from their targets in the nucleus. For example, induced translocation of ADAR2 (and likely also the short p110 form of ADAR1) from the nucleolus can increase activity at editing sites (Desterro et al., 2003; Sansam et al., 2003). However, contextual examples for this type of regulation in the nervous system remain elusive. Another example is the cytoplasmically localized p150 form of ADAR1, which is transcribed from an interferon-inducible promoter and can undergo regulated expression in some tissues, although not in the brain (Shtrichman et al., 2002; George et al., 2005). Further clues from pathology may reveal more candidate mechanisms relevant to physiological ADAR control. One example is the potential ADAR2 regulation by CA1-specific changes of cAMP-response element-binding protein (CREB) activity that occur following transient ischemic insults (Peng et al., 2006; Kitagawa, 2007). Consistent with these suggestions, the ADAR2 promoter contains a CREB/AP-1 binding site, which incidentally has shown necessary for ADAR2 regulation in glucose-responsive pancreatic cells via the stress-activated protein kinase JNK1 pathway (Yang et al., 2012). Furthermore, a link between calcium signaling via L-type voltage-gated calcium channels and activation of nuclear CREB might be key to understanding activity-dependent changes in ADAR2 expression (Wheeler et al., 2008; Balik et al., 2013). Challenges lie ahead to identify and detail the potential routes of ADAR regulation that are physiologically most relevant in different nervous system contexts. 


\section{HIGH-THROUGHPUT SEOUENCING AND EDITING IN NON-CODING REGIONS}

The lack of a clear signature for potential editing sites in gene sequence was limiting for the identification of new RNA editing sites (Hoopengardner et al., 2003). Before high-throughput sequencing techniques were available, a systematic search for new sites was based on computational analysis of the available databases containing genomic and transcriptional data. For example, human expressed sequence tags (ESTs) and cDNA data were aligned to genomic sequences to yield the discovery of four new genes subjected to editing (Clutterbuck et al., 2005; Levanon et al., 2005). However, these approaches were clearly limited as evidenced by the fact that they failed to identify all previously known editing sites. What these approaches did reveal though is that recoding sites are just the tip of the iceberg and that the majority of editing occurs in non-coding regions, which are vastly enriched in Alu repetitive elements (Athanasiadis et al., 2004; Blow et al., 2004; Kim et al., 2004; Levanon et al., 2004). These findings explained the abundance of inosine in brain mRNA (Paul and Bass, 1998) and confirmed experimental findings of editing in non-coding regions (Morse et al., 2002). Moreover, since Alu elements are primate-specific and account for $>10 \%$ of the human genome, A-to-I substitutions are significantly more abundant in primates (Eisenberg et al., 2005). The specific role of these non-coding edits on nervous system operation has not been elucidated. The high abundance of Alus, particularly in gene-enriched regions, will increase the probability for oppositely oriented Alus to anneal into dsRNA secondary structures thus serving as substrates for editing. Alterations of the stability of edited dsRNA structures will affect global RNA metabolism via a link with RNA interference (e.g., Bass, 2006). The advent of high-throughput sequencing technology has led to further advances in our understanding of editing at the genome level and facilitated verification of candidate sites ( $\mathrm{Li}$ et al., 2009; Wahlstedt et al., 2009), has revealed the interdependence or coupling of multiple editing sites

\section{REFERENCES}

Athanasiadis, A., Rich, A., and Maas, S. (2004). Widespread A-to-I RNA editing of Alu-containing mRNAs in the human transcriptome. PLoS Biol. 2:e391. doi: 10.1371/journal.pbio.0020391

Bahn, J. H., Lee, J.-H., Li, G., Greer, C., Peng, G., and Xiao, X. (2012). Accurate identification of A-to-I RNA editing in human by transcriptome sequencing. Genome Res. 22, 142-150.

Balik, A., Penn, A. C., Nemoda, Z., and Greger, I. H. (2013). Activityregulated RNA editing in select neuronal subfields in hippocampus. Nucleic Acids Res. 41, 1124-1134.

Bass, B. L. (2006). How does RNA editing affect dsRNA-mediated gene silencing? Cold Spring Harb. Symp. Quant. Biol. 71, 285-292.

Bernard, A., and Khrestchatisky, M. (1994). Assessing the extent of RNA editing in the TMII regions of GluR5 and GluR6 kainate receptors during rat brain development. J. Neurochem. 62, 2057-2060.

Bhalla, T., Rosenthal, J. J. C., Holmgren, M., and Reenan, R. (2004). Control of human potassium channel inactivation by editing of a small mRNA hairpin. Nat. Struct. Mol. Biol. 11, 950-956.

Bhansali, P., Dunning, J., Singer, S. E., David, L., and Schmauss, C. (2007). Early life stress alters adult serotonin $2 \mathrm{C}$ receptor pre-mRNA editing and expression of the alpha subunit of the heterotrimeric G-protein G q. J. Neurosci. 27, 1467-1473.

Blow, M., Futreal, P. A., Wooster, R., and Stratton, M. R. (2004). A survey of RNA editing in human brain. Genome Res. 14, 2379-2387.

Borchert, G. M., Gilmore, B. L., Spengler, R. M., Xing, Y., Lanier,

within a transcript (Ensterö et al., 2009), clarified the sequence and structural determinants for editing (Bahn et al., 2012) and enabled a comparison of the sites and frequency of edits between genomes (Danecek et al., 2012). The ongoing efforts of consortia like ENCODE and the 1000 Genomes Project will undoubtedly advance these fronts further (Djebali et al., 2012; Park et al., 2012).

\section{OUTLOOK}

As the discovery of new editing sites continues, so does the need to understand their function, and regulation, in maintaining normal neurophysiology and in mediating adaptability during neuronal plasticity. It is increasingly apparent that the impact of ADARs is widespread, diverse, and under dynamic control, thus the need to dissect the functions of individual editing sites is apparent. Animal models are going some way to achieve this and their contribution to our current understanding have been reviewed (e.g., Rula and Emeson, 2007 and references therein). Recently, new manipulations have emerged that could improve the throughput for investigating the functions of A-to-I editing events, such as the use of substrate-specific helix-threading peptides (Schirle et al., 2010) and steric antisense oligonucleotides (Mizrahi et al., 2013; Penn et al., 2013). Recent advances in the delivery of oligonucleotides using cell-penetrating peptides brings researchers closer to applying these manipulations in vivo more routinely (Järver et al., 2012; Moulton, 2012). In the future, these tools together with the increasing capacity of high-throughput resources might lead to therapeutic approaches that could correct defective editing associated with neurological diseases in humans.

\section{ACKNOWLEDGMENTS}

We thank Michael Jantsch (Vienna University) for critically reading of this manuscript and the MRC for funding our research and with institutional support RVO:67985823 (to Ales Balik).

W., Bhattacharya, D., et al. (2009). Adenosine deamination in human transcripts generates novel microRNA binding sites. Hum. Mol. Genet. 18, 4801-4807.

Brusa, R., Zimmermann, F., Koh, D. S., Feldmeyer, D., Gass, P., Seeburg, P. H., et al. (1995). Early-onset epilepsy and postnatal lethality associated with an editing-deficient GluR-B allele in mice. Science 270, 1677-1680.

Burnashev, N., Monyer, H., Seeburg, P. H., and Sakmann, B. (1992). Divalent ion permeability of AMPA receptor channels is dominated by the edited form of a single subunit. Neuron 8, 189-198.

Burns, C. M., Chu, H., Rueter, S. M., Hutchinson, L. K., Canton, H., Sanders-Bush, E., et al. (1997). Regulation of serotonin-2C receptor G-protein coupling by RNA editing. Nature 387, 303-308.
Chen, C. X., Cho, D. S., Wang, Q., Lai, F., Carter, K. C., and Nishikura, K. (2000). A third member of the RNA-specific adenosine deaminase gene family, ADAR3, contains both single- and double-stranded RNA binding domains. RNA 6, 755-767.

Clutterbuck, D. R., Leroy, A., O'Connell, M. A., and Semple, C. A. (2005). A bioinformatic screen for novel A-I RNA editing sites reveals recoding editing in $\mathrm{BC} 10$. Bioinformatics 21, 2590-2595.

Colina, C., Palavicini, J. P., Srikumar, D., Holmgren, M., and Rosenthal, J. J. C. (2010). Regulation of $\mathrm{Na}+\mathrm{K}+$ ATPase transport velocity by RNA editing. PLoS Biol. 8:e1000540. doi: 10.1371/journal.pbio. 1000540

Danecek, P., Nellåker, C., McIntyre, R. E., Buendia-Buendia, J. E., Bumpstead, S., Ponting, C. P., et al. (2012). High levels of RNA-editing site conservation 
amongst 15 laboratory mouse strains. Genome Biol. 13:r26. doi: 10.1186/gb-2012-13-4-r26

Desterro, J. M. P., Keegan, L. P., Jaffray, E., Hay, R. T., O’Connell, M. A., and Carmo-Fonseca, M. (2005). SUMO-1 modification alters ADARl editing activity. Mol. Biol. Cell 16, 5115-5126.

Desterro, J. M. P., Keegan, L. P., Lafarga, M., Berciano, M. T., O’Connell, M., and Carmo-Fonseca, M. (2003). Dynamic association of RNAediting enzymes with the nucleolus. J. Cell Sci. 116, 1805-1818.

Djebali, S., Davis, C. A., Merkel, A., Dobin, A., Lassmann, T., Mortazavi, A., et al. (2012). Landscape of transcription in human cells. Nature 489, 101-108.

Doe, C. M., Relkovic, D., Garfield, A. S., Dalley, J. W., Theobald, D. E. H., Humby, T., et al. (2009). Loss of the imprinted snoRNA mbii-52 leads to increased 5 htr $2 \mathrm{c}$ pre-RNA editing and altered 5HT2CR-mediated behaviour. Hum. Mol. Genet. 18, 2140-2148.

Eisenberg, E., Nemzer, S., Kinar, Y., Sorek, R., Rechavi, G., and Levanon, E. Y. (2005). Is abundant A-toI RNA editing primate-specific? Trends Genet. 21, 77-81.

Ekdahl, Y., Farahani, H. S., Behm, M., Lagergren, J., and Öhman, M. (2012). A-to-I editing of microRNAs in the mammalian brain increases during development. Genome Res. 22, 1477-1487.

Englander, M. T., Dulawa, S. C., Bhansali, P., and Schmauss, C. (2005). How stress and fluoxetine modulate serotonin $2 \mathrm{C}$ receptor pre-mRNA editing. J. Neurosci. 25, 648-651.

Ensterö, M., Daniel, C., Wahlstedt, H., Major, F., and Ohman, M. (2009). Recognition and coupling of A-toI edited sites are determined by the tertiary structure of the RNA. Nucleic Acids Res. 37, 6916-6926.

Feng, Y., Sansam, C. L., Singh, M., and Emeson, R. B. (2006). Altered RNA editing in mice lacking ADAR2 autoregulation. Mol. Cell Biol. 26, 480-488.

Flomen, R., Knight, J., Sham, P., Kerwin, R., and Makoff, A. (2004). Evidence that RNA editing modulates splice site selection in the 5HT2C receptor gene. Nucleic Acids Res. 32, 2113-2122.

Garrett, S., and Rosenthal, J. J. C. (2012). RNA editing underlies temperature adaptation in $\mathrm{K}+$ channels from polar octopuses. Science 335, 848-851.

George, C. X., Gan, Z., Liu, Y., and Samuel, C. E. (2011). Adenosine deaminases acting on RNA, RNA editing, and interferon action. J. Interferon Cytokine Res. 31, 99-117.

George, C. X., Wagner, M. V., and Samuel, C. E. (2005). Expression of interferon-inducible RNA adenosine deaminase ADAR1 during pathogen infection and mouse embryo development involves tissue-selective promoter utilization and alternative splicing. J. Biol. Chem. 280, 15020-15028.

Greger, I. H., Khatri, L., and Ziff, E. B. (2002). RNA editing at Arg607 controls AMPA receptor exit from the endoplasmic reticulum. Neuron 30, 759-772.

Grohmann, M., Hammer, P., Walther, M., Paulmann, N., Büttner, A., Eisenmenger, W., et al. (2010). Alternative splicing and extensive RNA editing of human TPH2 transcripts. PLOS ONE 5:e8956. doi: 10.1371/journal.pone.0008956

Gurevich, I., Englander, M. T., Adlersberg, M., Siegal, N. B., and Schmauss, C. (2002). Modulation of serotonin $2 \mathrm{C}$ receptor editing by sustained changes in serotonergic neurotransmission. J. Neurosci. 22, 10529-10532.

Hang, P. N. T., Tohda, M., and Matsumoto, K. (2008). Developmental changes in expression and self-editing of adenosine deaminase type 2 pre-mRNA and mRNA in rat brain and cultured cortical neurons. Neurosci. Res. 61, 398-403.

Heale, B. S. E., Keegan, L. P., McGurk, L., Michlewski, G., Brindle, J., Stanton, C. M., et al. (2009). Editing independent effects of ADARs on the miRNA/siRNA pathways. EMBO J. 28, 3145-3156.

Hideyama, T., Yamashita, T., Aizawa, H., Tsuji, S., Kakita, A., Takahashi, H., et al. (2012). Profound downregulation of the RNA editing enzyme ADAR2 in ALS spinal motor neurons. Neurobiol. Dis. 45, 1121-1128.

Hideyama, T., Yamashita, T., Suzuki, T., Tsuji, S., Higuchi, M., Seeburg, P. H., et al. (2010). Induced loss of ADAR2 engenders slow death of motor neurons from $Q / R$ siteunedited GluR2. J. Neurosci. 30, 11917-11925.

Higuchi, M., Maas, S., Single, F. N., Hartner, J., Rozov, A., Burnashev, N., et al. (2000). Point mutation in an AMPA receptor gene rescues lethality in mice deficient in the RNA-editing enzyme ADAR2. Nature 406, 78-81.

Hoopengardner, B., Bhalla, T., Staber, C., and Reenan, R. (2003). Nervous system targets of RNA editing identified by comparative genomics. Science 301, 832-836.

Horsch, M., Seeburg, P. H., Adler, T., Aguilar-Pimentel, J. A., Becker, L., Calzada-Wack, J., et al. (2011). Requirement of the RNA-editing enzyme ADAR2 for normal physiology in mice. J. Biol. Chem. 286, 18614-18622.

Huang, H., Tan, B. Z., Shen, Y., Tao, J., Jiang, F., Sung, Y. Y., et al. (2012). RNA editing of the IQ domain in $\mathrm{Ca}(\mathrm{v}) 1.3$ channels modulates their $\mathrm{Ca} 2+$-dependent inactivation. Neuron 73, 304-316.

Irimia, M., Denuc, A., Ferran, J. L., Pernaute, B., Puelles, L., Roy, S. W., et al. (2012). Evolutionarily conserved A-to-I editing increases protein stability of the alternative splicing factor Noval. RNA Biol. 9, 12-21.

Jacobs, M. M., Fogg, R. L., Emeson, R. B., and Stanwood, G. D. (2009). ADAR1 and ADAR2 expression and editing activity during forebrain development. Dev. Neurosci. 31, 223-237.

Järver, P., Coursindel, T., Andaloussi, S E., Godfrey, C., Wood, M. J., and Gait, M. J. (2012). Peptide-mediated cell and in vivo delivery of antisense oligonucleotides and siRNA. Mol. Ther. Nucleic Acids 1:e27. doi: 10.1038/mtna.2012.18

Jensen, K. B., Dredge, B. K., Stefani, G., Zhong, R., Buckanovich, R. J., Okano, H. J., et al. (2000). Nova-1 regulates neuron-specific alternative splicing and is essential for neuronal viability. Neuron 25, 359-371.

Jepson, J. E. C., and Reenan, R. A. (2008). RNA editing in regulating gene expression in the brain. Biochim. Biophys. Acta 1779, 459-470.

Kawahara, Y., Zinshteyn, B. Sethupathy, P., Iizasa, H., Hatzigeorgiou, A. G., and Nishikura, K. (2007). Redirection of silencing targets by adenosine-to-inosine editing of miRNAs. Science 315, 1137-1140.

Kim, D. D. Y., Kim, T. T. Y., Walsh, T., Kobayashi, Y., Matise, T. C., Buyske, S., et al. (2004). Widespread RNA editing of embedded alu elements in the human transcriptome. Genome Res. 14, 1719-1725.

Kishore, S., and Stamm, S. (2006). The snoRNA HBII-52 regulates alternative splicing of the serotonin receptor 2C. Science 311, 230-232.

Kitagawa, K. (2007). CREB and cAMP response element-mediated gene expression in the ischemic brain. FEBS J. 274, 3210-3217.
Köhler, M., Burnashev, N., Sakmann, B., and Seeburg, P. H. (1993). Determinants of $\mathrm{Ca} 2+$ permeability in both TM1 and TM2 of high affinity kainate receptor channels: diversity by RNA editing. Neuron 10, 491-500.

Krestel, H. E., Shimshek, D. R., Jensen, V., Nevian, T., Kim, J., Geng, Y., et al. (2004). A genetic switch for epilepsy in adult mice. J. Neurosci. 24, 10568-10578.

Levanon, E. Y., Eisenberg, E., Yelin, R. Nemzer, S., Hallegger, M., Shemesh, R., et al. (2004). Systematic identification of abundant A-to-I editing sites in the human transcriptome. Nat. Biotechnol. 22, 1001-1005.

Levanon, E. Y., Hallegger, M., Kinar, Y., Shemesh, R., Djinovic-Carugo, K., Rechavi, G., et al. (2005). Evolutionarily conserved human targets of adenosine to inosine RNA editing. Nucleic Acids Res. 33, 1162-1168.

Li, J. B., Levanon, E. Y., Yoon, J.-K., Aach, J., Xie, B., Leproust, E., et al. (2009). Genome-wide identification of human RNA editing sites by parallel DNA capturing and sequencing. Science 324, 1210-1213.

Lim, L. P., Lau, N. C., Garrett-Engele, P., Grimson, A., Schelter, J. M., Castle, J., et al. (2005). Microarray analysis shows that some microRNAs downregulate large numbers of target mRNAs. Nature 433, 769-773.

Lomeli, H., Mosbacher, J., Melcher, T. Höger, T., Geiger, J. R., Kuner, T., et al. (1994). Control of kinetic properties of AMPA receptor channels by nuclear RNA editing. Science 266, 1709-1713.

Maas, S. (2010). Gene regulation through RNA editing. Discov. Med. 10, 379-386.

Maas, S., Kawahara, Y., Tamburro, K. M., and Nishikura, K. (2006). A-toI RNA editing and human disease. RNA Biol. 3, 1-9.

MacBeth, M. R., Schubert, H. L., Vandemark, A. P., Lingam, A. T. Hill, C. P., and Bass, B. L. (2005). Inositol hexakisphosphate is bound in the ADAR2 core and required for RNA editing. Science 309, 1534-1539.

Marcucci, R., Brindle, J., Paro, S. Casadio, A., Hempel, S., Morrice, N., et al. (2011). Pin1 and WWP2 regulate GluR2 Q/R site RNA editing by ADAR2 with opposing effects. EMBO J. 30, 4211-4222.

Mizrahi, R. A., Schirle, N. T., and Beal, P. A. (2013). Potent and selective inhibition of A-to-I RNA editing with 2 '-O-Methyl/Locked Nucleic 
Acid-containing antisense oligoribonucleotides. ACS Chem. Biol. doi: 10.1021/cb300692k. [Epub ahead of print].

Morabito, M. V., Abbas, A. I., Hood, J. L., Kesterson, R. A., Jacobs, M. M., Kump, D. S., et al. (2010). Mice with altered serotonin $2 \mathrm{C}$ receptor RNA editing display characteristics of Prader-Willi syndrome. Neurobiol. Dis. 39, 169-180.

Morse, D. P., Aruscavage, P. J., and Bass, B. L. (2002). RNA hairpins in noncoding regions of human brain and Caenorhabditis elegans mRNA are edited by adenosine deaminases that act on RNA. Proc. Natl. Acad. Sci. U.S.A. 99, 7906-7911.

Moulton, H. M. (2012). In vivo delivery of morpholino oligos by cellpenetrating peptides. Curr. Pharm. Des. [Epub ahead of print].

Nishikura, K. (2010). Functions and regulation of RNA editing by ADAR deaminases. Annu. Rev. Biochem. 79, 321-349.

Ohlson, J., Pedersen, J. S., Haussler, D., and Ohman, M. (2007). Editing modifies the $\mathrm{GABA}(\mathrm{A})$ receptor subunit alpha3. RNA 13, 698-703.

O’Neil, R. T., and Emeson, R. B. (2012). Quantitative analysis of $5 \mathrm{HT}(2 \mathrm{C})$ receptor RNA editing patterns in psychiatric disorders. Neurobiol. Dis. 45, 8-13.

Orlandi, C., La Via, L., Bonini, D., Mora, C., Russo, I., Barbon, A., et al. (2011). AMPA receptor regulation at the mRNA and protein level in rat primary cortical cultures. PLoS ONE 6:e25350. doi: 10.1371/journal.pone.0025350

Park, E., Williams, B., Wold, B. J., and Mortazavi, A. (2012). RNA editing in the human ENCODE RNA-seq data. Genome Res. 22, 1626-1633.

Paul, M. S., and Bass, B. L. (1998). Inosine exists in mRNA at tissuespecific levels and is most abundant in brain mRNA. EMBO J. 17, 1120-1127.

Paupard, M.-C., O'Connell, M. A., Gerber, A. P., and Zukin, R. S. (2000). Patterns of developmental expression of the RNA editing enzyme rADAR2. Neuroscience 95, 869-879.

Peng, P. L., Zhong, X., Tu, W., Soundarapandian, M. M., Molner, P., Zhu, D., et al. (2006). ADAR2dependent RNA editing of AMPA receptor subunit GluR2 determines vulnerability of neurons in forebrain ischemia. Neuron 49, 719-733.

Penn, A. C., Balik, A., and Greger, I. H. (2013). Steric antisense inhibition of AMPA receptor $Q / R$ editing reveals tight coupling to intronic editing sites and splicing. Nucleic Acids Res. 41, 1113-1123.

Penn, A. C., Balik, A., Wozny, C., Cais, O., and Greger, I. H. (2012). Activity-mediated AMPA receptor remodeling, driven by alternative splicing in the ligand-binding domain. Neuron 76, 503-510.

Rieder, L. E., and Reenan, R. A. (2012). The intricate relationship between RNA structure, editing, and splicing. Semin. Cell Dev. Biol. 23, 281-288.

Rosenthal, J. J. C., and Bezanilla, F. (2002). Extensive editing of mRNAs for the squid delayed rectifier $\mathrm{K}+$ channel regulates subunit tetramerization. Neuron 34, 743-757.

Rosenthal, J. J. C., and Seeburg, P. H. (2012). A-to-I RNA editing: effects on proteins key to neural excitability. Neuron 74, 432-439.

Rueter, S. M., Dawson, T. R., and Emeson, R. B. (1999). Regulation of alternative splicing by RNA editing. Nature 399, 75-80.

Rula, E. Y., and Emeson, R. B. (2007). Mouse models to elucidate the functional roles of adenosine-toinosine editing. Methods Enzymol. 424, 333-367.

Rula, E. Y., Lagrange, A. H., Jacobs, M. M., Hu, N., Macdonald, R. L., and Emeson, R. B. (2008). Developmental modulation of $\mathrm{GABA}(\mathrm{A})$ receptor function by RNA editing. J. Neurosci. 28, 6196-6201.

Sanjana, N. E., Levanon, E. Y., Hueske, E. A., Ambrose, J. M., and Li, J. B. (2012). Activity-dependent A-toI RNA editing in rat cortical neurons. Genetics 192, 281-287.

Sansam, C. L., Wells, K. S., and Emeson, R. B. (2003). Modulation of RNA editing by functional nucleolar sequestration of ADAR2. Proc. Natl. Acad. Sci. U.S.A. 100, 14018-14023.

Schirle, N. T., Goodman, R. A., Krishnamurthy, M., and Beal, P. A. (2010). Selective inhibition of ADAR2-catalyzed editing of the serotonin $2 \mathrm{c}$ receptor
pre-mRNA by a helix-threading peptide. Org. Biomol. Chem. 8, 4898-4904.

Schmauss, C., Zimnisky, R., Mehta M., and Shapiro, L. P. (2010). The roles of phospholipase C activation and alternative ADAR1 and ADAR2 pre-mRNA splicing in modulating serotonin 2Creceptor editing in vivo. RNA 16, 1779-1785.

Schoft, V. K., Schopoff, S., and Jantsch, M. F. (2007). Regulation of glutamate receptor B pre-mRNA splicing by RNA editing. Nucleic Acids Res. 35, 3723-3732.

Shtrichman, R., Heithoff, D. M., Mahan, M. J., and Samuel, C. E. (2002). Tissue selectivity of interferon-stimulated gene expression in mice infected with $\operatorname{Dam}(+)$ versus Dam(-) Salmonella enterica serovar Typhimurium strains. Infect. Immun. 70, 5579-5588.

Slavov, D., and Gardiner, K. (2002). Phylogenetic comparison of the pre-mRNA adenosine deaminase ADAR2 genes and transcripts: conservation and diversity in editing site sequence and alternative splicing patterns. Gene 299, 83-94.

Sommer, B., Köhler, M., Sprengel, R., and Seeburg, P. H. (1991). RNA editing in brain controls a determinant of ion flow in glutamate-gated channels. Cell 67, 11-19.

Tariq, A., Garncarz, W., Handl, C., Balik, A., Pusch, O., and Jantsch, M. F. (2013). RNA-interacting proteins act as site specific repressors of ADAR2 mediated RNAediting and fluctuate upon neuronal stimulation. Nucleic Acids Res. 41, 2581-2593.

Ule, J., Ule, A., Spencer, J., Williams, A., Hu, J.-S., Cline, M., et al. (2005). Nova regulates brain-specific splicing to shape the synapse. Nat. Genet. 37, 844-852.

Vesely, C., Tauber, S., Sedlazeck, F. J., Von Haeseler, A., and Jantsch, M. F. (2012). Adenosine deaminases that act on RNA induce reproducible changes in abundance and sequence of embryonic miRNAs. Genome Res. 22, 1468-1476.

Wahlstedt, H., Daniel, C., Ensterö, M., and Ohman, M. (2009). Largescale mRNA sequencing determines global regulation of RNA editing during brain development. Genome Res. 19, 978-986.

Wheeler, D. G., Barrett, C. F., Groth, R. D., Safa, P., and Tsien, R. W. (2008). CaMKII locally encodes L-type channel activity to signal to nuclear CREB in excitationtranscription coupling. J. Cell Biol. 183, 849-863.

Yang, L., Huang, P., Li, F., Zhao, L., Zhang, Y., Li, S., et al. (2012). c-Jun amino-terminal kinase1 mediates glucose-responsive upregulation of the RNA editing enzyme ADAR2 in pancreatic beta-cells. PLoS ONE 7:e48611. doi: 10.1371/journal.pone.0048611

Yang, W., Chendrimada, T. P., Wang, Q., Higuchi, M., Seeburg, P. H., Shiekhattar, R., et al. (2006). Modulation of microRNA processing and expression through RNA editing by ADAR deaminases. Nat. Struct. Mol. Biol. 13, 13-21.

Zhang, X., Beaulieu, J.-M., Sotnikova, T. D., Gainetdinov, R. R., and Caron, M. G. (2004). Tryptophan hydroxylase-2 controls brain serotonin synthesis. Science $305,217$.

Conflict of Interest Statement: The authors declare that the research was conducted in the absence of any commercial or financial relationships that could be construed as a potential conflict of interest.

Received: 25 February 2013; paper pending published: 22 March 2013; accepted: 02 April 2013; published online: 18 April 2013.

Citation: Penn AC, Balik A and Greger IH (2013) Reciprocal regulation of A-toI RNA editing and the vertebrate nervous system. Front. Neurosci. 7:61. doi: 10.3389/fnins.2013.00061

This article was submitted to Frontiers in Neurogenomics, a specialty of Frontiers in Neuroscience.

Copyright (c) 2013 Penn, Balik and Greger. This is an open-access article distributed under the terms of the Creative Commons Attribution License, which permits use, distribution and reproduction in other forums, provided the original authors and source are credited and subject to any copyright notices concerning any third-party graphics etc. 